\title{
Using XFEM to predict the damage with temperature of the steel pipe elbows under bending and pressure loading
}

\author{
N. Hammadi, M. Mokhtari \\ Laboratoire La RTFM, Ecole Nationale Polytechnique Maurice Audin, Oran, Algeria \\ hammadi.nourddine@grtg.dz \\ mokbtarimohamed44@yahoo.fr, bttps://orcid.org/0000-0002-2014-1172
}

H. Benzaama

Laboratoire LABAB, Ecole Nationale Polytechnique Maurice Audin, Oran, Algeria babenza@yahoo.fr, bttps://orcid.org/0000-0002-7145-3758

K. Madani

Laboratoire Mécanique Physique des Matériaux (LMPM), Sidi Bel Abbes, Algeria

koumad10@yahoo.fr, https://orcid.org/0000-0003-3277-1187

\author{
A. Brakna \\ Laboratoire La RTFM, Ecole Nationale Polytechnique Maurice Audin, Oran, Algeria \\ aek.kaki829@gmail.com \\ E. Abdelouahed \\ Laboratoire LABAB, Ecole Nationale Polytechnique Maurice Audin, Oran, Algeria \\ beabamine@gmail.com, bttps:/ /orcid.org/0000-0002-6923-5305
}

\begin{abstract}
The pipes, during their service, are subjected to accumulated loads such as internal pressure and that of the soil. The latter considerably accelerate their damage. In this work, the bending moment stress of API 5L X70 category steel elbows under thermo-mechanical behavior and in the presence of pressure were studied. We used FEM (finite element method) through the numerical calculation code ABAQUS and the XFEM technique for structural damage while using solid elements as a structure. Our objective is to evaluate the response and resistance capacity of the steel elbow by its location in the tube - elbow-tube system under a mixed loading of pressure and moment for all scenarios. It is based on a single standardized dimensioning of the elbow (diameter and thickness). The effect of several parameters has been studied such as the type of loading and the pressure levels, which are clearly conditioned by the level of damage. Numerical
\end{abstract}

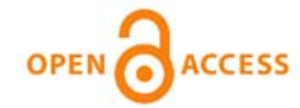

Citation: Hammadi, N., Mokhtari, M., Benzaama, H., Madani, K., Brakna, K., Abdelouahed, E., Using XFEM to predict the damage with temperature of the steel pipe elbows under bending and pressure loading, Frattura ed Integrità Strutturale, 55 (2021) 345359.

Received: 20.09 .2020

Accepted: 27.12.2020

Published: 01.01.2021

Copyright: (C) 2021 This is an open access article under the terms of the CC-BY 4.0, which permits unrestricted use, distribution, and reproduction in any medium, provided the original author and source are credited.
} 
damage results are presented by moment-rotation curves. They illustrate the variation in damage as a function of these effects, which act simultaneously.

KEYWORDS. FEM (Finite Element Method); XFEM (extended finite element modeling); Damage.

\section{INTRODUCTION}

$\mathrm{T}$ he elbow, in its geometric configuration, will cause a variation in stress along its lower surface and upper surface and by several possible loading conditions, giving rise to several types of damage. Several researches have been focused on the understanding of the mechanical behavior of these elbows; these researches were started by the analytical work of Von Karman [1] where he used a formulation between the longitudinal deformation due to bending and that due to ovalization.

Rodabaugh and George [2], improved this solution by introducing internal pressure. Other researchers such as Karamanos and Shalaby [3], concluded that under heavy loading the elbow ovalization due to stresses and strains is greater in the circumference than in the longitudinal. They also concluded that the response under closing bending moments is different from that of opening. Due to the different signs of ovalization, a series of tests in summer carried out by Sobel and Newman [4] and Dhalla [5] on the flexion response of the elbows under closing moments. Their results were compared with numerical results using shell elements. Others add pressure in tests such as Gresnigt et al [6] where they have developed with van Foeken [7] an analytical model for the transverse deformation of elbows by introducing a correction factor to take into account the influence of elbow parameters on its ovalization. The defect and the temperature by their presence strongly destabilize the elbows in their resistance and localize the damage as well as they condition the response of the structures to loading until their failure [8]. They appear in tubular structures as microcracks and or cavities or others. The location of these defects categorizes the mode of damage. Most of the time, they result in the degradation of their mechanical characteristics [9-10]. This is the reason why all these phenomena are the subject of numerous research studies applied to industry.

The study of these tubular structures is the subject of several researchers such as the work of Abdelouahed et al. [10] where they digitally analyzed the structure under pressure and damage moment by thermal effect and in the presence of defects. Shao [11] evaluated thermal stresses as well as Kandil et al. [12] by the digital model. Several researchers such as Greenstreet [13], Hilsenkopf, Suzuki and Nasu [14] experimentally tested elbows with different dimensions under different loading modes and compared their results by numerical methods. Others like Tan et al. [15] recently studied the bending and opening flexion of an elbow and compared it with finite element analysis results. Shalaby and Younan [16] analyzed 90 degrees steel elbows for a wide range of diameter / thickness ratios under in-plane bending moment in opening and closing with internal pressure. Karamanos et al. [17] studied the damage of non-pressurized buckling elbows numerically, a good comparison was found between the numerical results and the experimental tests. Greenstreet [13] and Hilsenkopf et al. [18] have also shown that 90 degrees elbows in out of plane loading undergo inelastic deformations before damage and that their capacity is affected by the presence of internal pressure. The first part of their work deals with its mechanical behavior with the presence of internal pressure, by analyzing the stresses in the structure requested under various loading conditions. The second part examines the effect of pressure and elbow angle on structural damage. Curves show the response of structures to loading until they fail.

\section{XFEM TECHNIQUE AND INPUT PARAMETER}

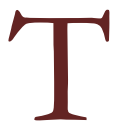
he structure is studied by the XFEM technique (extend finite element). This technique introduces an enrichment in the elements by an increase in the quality of approximation of the functions. These functions then make it possible to easily initiate and predict the propagation path of the crack and it is implemented in the standard ABAQUS computation code [19]. The following analysis using this technique XFEM uses the elastic properties presented in table 1. The maximum principal stress is the value of the nominal strength, which is measured as $673.14 \mathrm{MPa}$. The damage evaluation criterion is maximum traction displacement (maximum crack opening of steel X70 measured as $4.2 \mathrm{~mm}$ ). The damage is continuous throughout the structure by crack propagation resulting in a separation in the structure regardless of the 
architectural mesh. This crack propagation in the structure subsequently gives a degradation of the rigidity, which explains the drop in the response of structure under loading, presented in this study by the load-displacement curves. In the XFEM technique, damage takes the following forms:

$*$ Enrichment, name $=$ Crack -1 , type $=$ PROPAGATION CRACK, activate $=$ ON

Reliable numerical calculations are obtained by the choice of solid elements in three dimensions. There is no presence of cracks or defects in the structure. Crack initiation and propagation occur when the structure detects pre-loading failure parameters. The parameters of numerical computation were in good agreement with the convergence of computation and with an optimal time. This allowed us to deepen the different effects on the resistance of our studied structure. These effects are hardly supported by numerical calculations using other criteria. The crack initiation criterion used in this analysis named MAXS “The maximum nominal Stress Criterion" is integrated into the ABAQUS Standard calculation code:

$$
f=\max \left(\frac{\left(t_{n}\right)}{t_{n}^{0}}, \frac{t_{s}}{t_{s}^{0}}, \frac{t_{t}}{t_{t}^{0}}\right)
$$

$t_{n}, t_{s}, t_{t}$ represent respectively the nominal stresses normal and tangential to the two directions $(\mathrm{x})$ and $(\mathrm{y})$.

$t_{n}^{0}, t_{s}^{0}, t_{t}^{0}$ respectively represent the maximum normal and tangential stresses to the two directions $(\mathrm{x})$ and $(\mathrm{y})$.

The initiation of the damage is done without taking into account the purely compressive stresses, and it is in the case where the maximum nominal stress ratio $\mathrm{f}=1$.

The damage evolution law describes the rate at which the material stiffness is degraded once the corresponding initiation criterion is reached. A scalar damage variable, $\mathrm{D}$, represents the overall damage in the material and captures the combined effects of all the active mechanisms. It initially has a value of zero. If damage evolution is modeled, D monotonically evolves from zero to one upon further loading after the initiation of damage. The stress components are affected by the damage according to:

$$
\begin{aligned}
& t_{n}=\left\{(1-D) \underline{t_{n}}, \quad \underline{t_{n}}>0 \underline{t_{n}}>0,\right. \text { no damage to compressive stiffness } \\
& t_{s}=(1-D) \underline{t_{s}} \\
& t_{t}=(1-D) \underline{t_{t}}
\end{aligned}
$$

where $\underline{t}_{\underline{n}}, \underline{t_{n}}$ and $\underline{t_{t}}$ are the stress components predicted by the elastic traction-separation behavior for the current strains without damage.

The procedure below includes data entries of damage evolution available in the Property module. We use displacement as Type of damage evolution, it defines damage as a function of the total plastic for bulk elastic-plastic materials, displacement after damage initiation. This type corresponds to the Displacement at Failure field in the Data table introduced in the calculation code.

$$
\delta m=\sqrt{(\delta n)^{2}+\delta s^{2}+\delta t^{2}}
$$

represents the mixed displacement at failure.

$\delta \mathrm{n}, \delta$ s and $\delta \mathrm{s}$ represent respectively the normal and tangential displacement at failure.

These damage models exhibit softening and stiffness degradation behavior, which often lead to convergence difficulties. The viscous regularization of the constitutive equations defining the behavior in an enriched element is used to overcome the difficulties of convergence. The damping of viscous regularization causes that the tangent stiffness matrix is positive definite for sufficiently small increments of time. A convergence stabilization coefficient was used when 0.00001 with an adequate time increment of $0.0001 \mathrm{~s}$ was introduced to avoid the damage moment underestimation. The parameters introduced in the ABAQUS calculation code are: 
$*$ Damage Initiation, criterion $=$ MAXS

$*$ Damage Evolution, type=DISPLACEMENT

*Damage Stabilization 1e-5

\section{DESCRIPTION OF MODEL GEOMETRY AND MATERIAL PROPERTIES}

he geometries of the analyzed structure are normalized [20] and illustrated in figures (1) and (2). The characteristics in elastic-plastic behavior and that of resistance are reported in figure (4) and in table (1). The elbow element is connected to two straight pipes of length $960 \mathrm{~mm}$. The length is sufficient to ensure that there is no stress interference in the elbow region from loads applied to the ends of the linear parts. It is assumed that no failure occurs at the elbow; the straight pipe only acts as a means of uniformly transferring the bending moments to the elbow bends. Numerically the bending moment load on the elbow was obtained by imposing a rotation around the elbow axis.
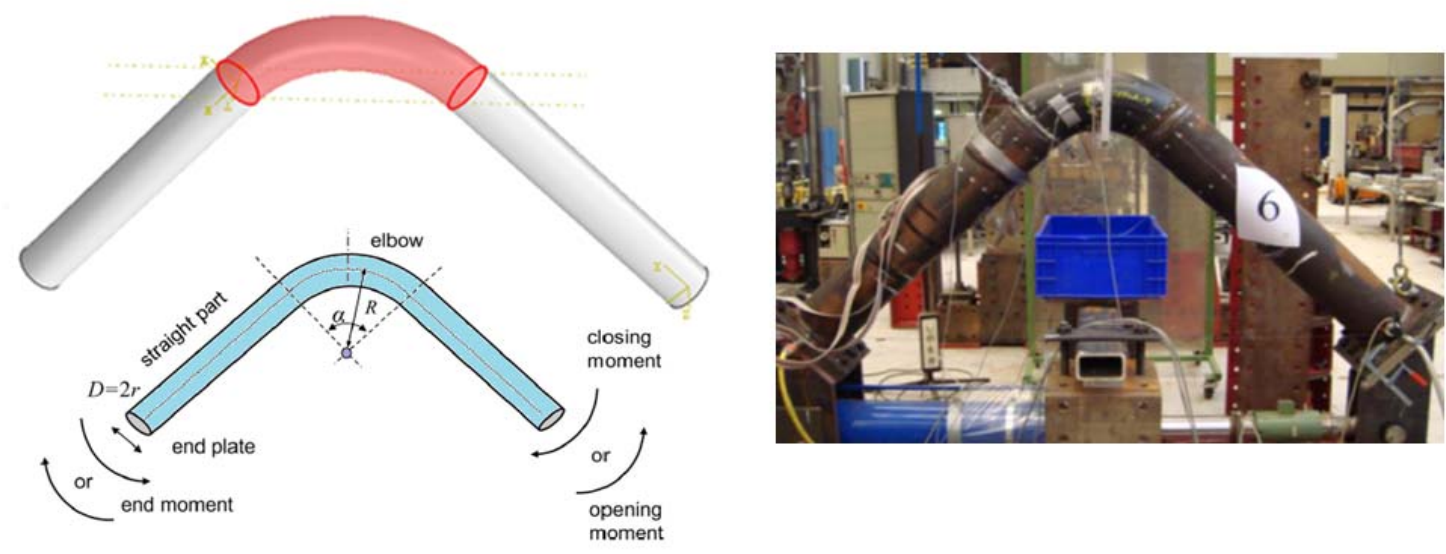

Figure 1: Overview of the studied geometry.

Tubular structures having the following dimensions: the diameter equal to $160 \mathrm{~mm}$ and the thickness equal to $6.4 \mathrm{~mm}$. For the three angles of the bend analyzed $30^{\circ}, 60^{\circ}$ and $90^{\circ}$, they have the same radius of curvature which is equal to $480 \mathrm{~mm}$. In order to compare them, these elbows are uniformly subjected to an imposed rotational displacement of $60^{\circ}$. In order to cause only damage, each bend is subjected in the structure by the three modes of bending in addition to three levels of pressure.
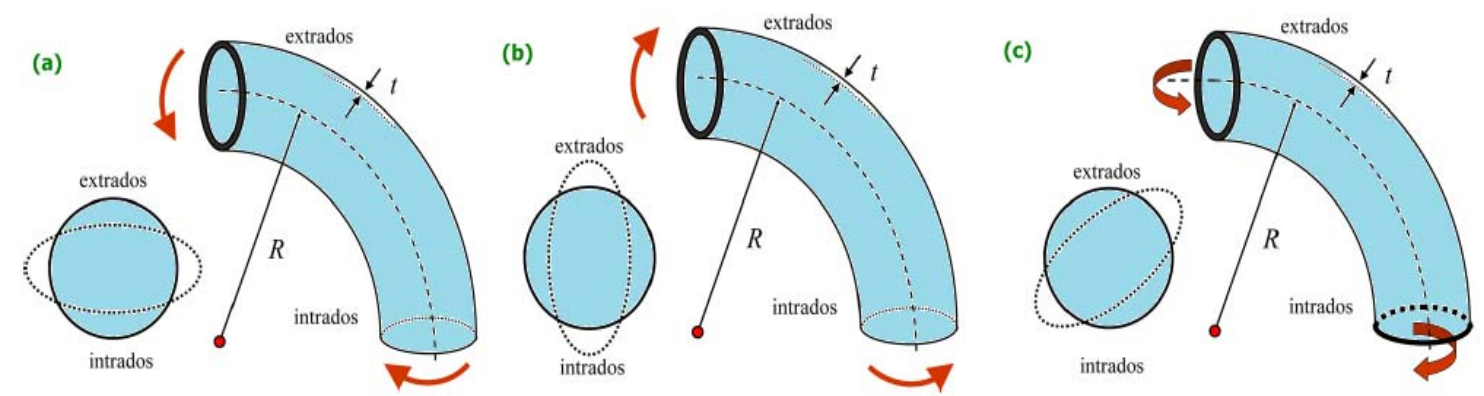

Figure 2: Schematic representation of ovalization in (a) in-plane closing moments, (b) out-of-plane opening moments reverse ovalization, and (c) out-of-plane bending

For all the situations studied, the elbows are under pressure with the presence of existent temperature in the tubular structure. For all the structures analyzed, they are subject to the same conditions. That is to say a fixation at the edge of the linear part in three displacements according to $\mathrm{x}, \mathrm{y}$ and $\mathrm{z}$. In the other linear part at the edge of the tube, a rotation is applied depending on the case studied in the direction of opening or closing of the cross section of the tube and around the radius of curvature of the elbow. This rotational displacement leads to damage to the structure. 

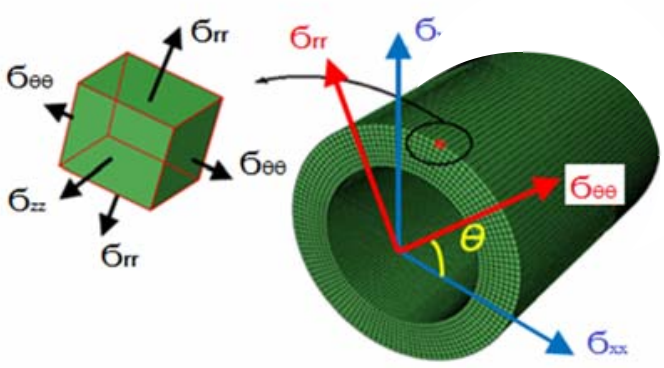
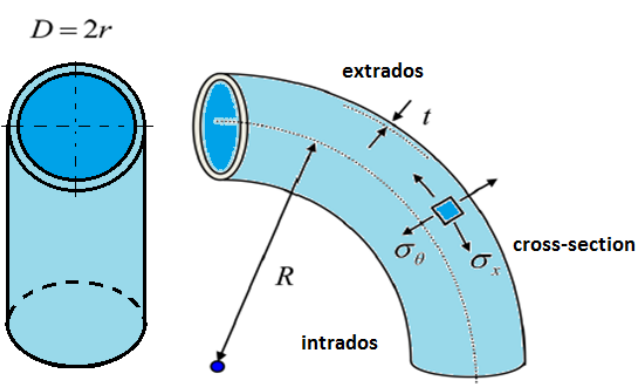

Figure 3: State of stress chowing in the elbow geometry and in each finite element.

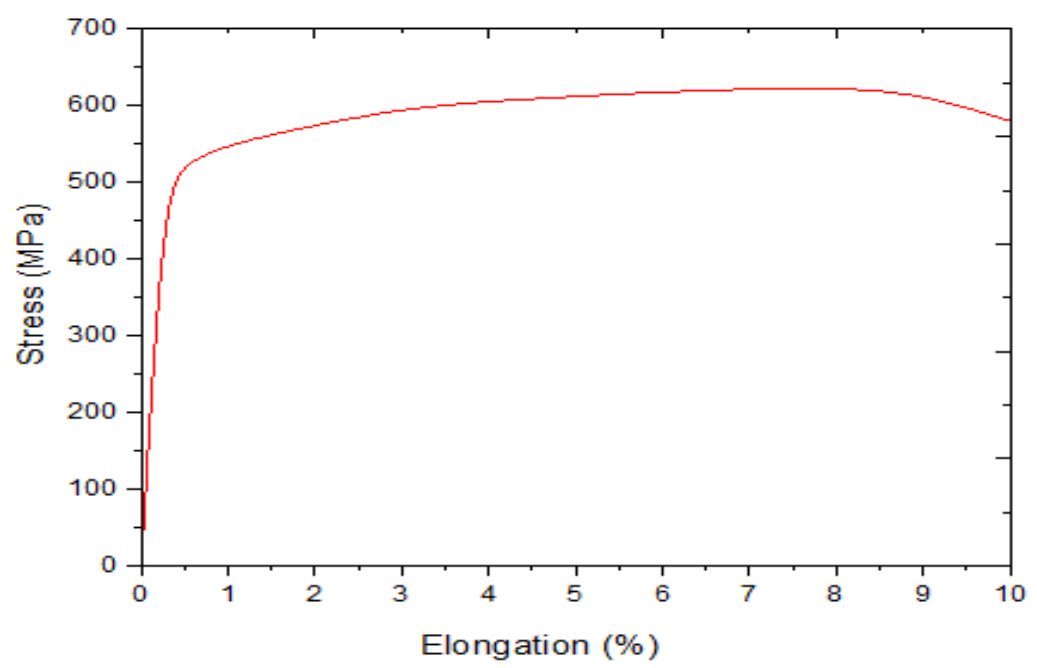

Figure 4: Experimental stress-strain curves for the elbow material.

The properties of API 5L X70 steel are chosen from the experimental work of Bouledroua [21]. This allowed us to use these parameters of stiffness, plasticity and strength. The properties are taken from the curve presented in figure (4); the maximum principal stress is the value of the nominal resistance, which takes a level of 673.14 MPa. The criterion for evaluating damage is the maximum tensile displacement (maximum crack opening of the steel at a level of $1 \mathrm{~mm}$ ).

\begin{tabular}{cc}
\hline Young's modulus E & $222 \mathrm{GPa}$ \\
Poisson ration & 0.3 \\
Yield stress & $483.03 \mathrm{MPa}$ \\
Maximum stress & $673.14 \mathrm{MPa}$ \\
Elongation \% & $40.55 \%$ \\
\hline
\end{tabular}

Table 1: Material mechanical properties of API 5L X70 steel

The mechanical properties of the experimental test performed by O. Bouledroua (2015), those of the elastic-plastic behavior and of the damage are for a straight tube. In our analysis, we opted for the same material for the whole structure, that of the elbow and the two linear parts. The effects studied on the structure damage were limited only on the three modes of loading choice: moment in closing and in opening and that of the moment out of plans while evaluating at the same time the pressure applied for each different case (elbow angle). 


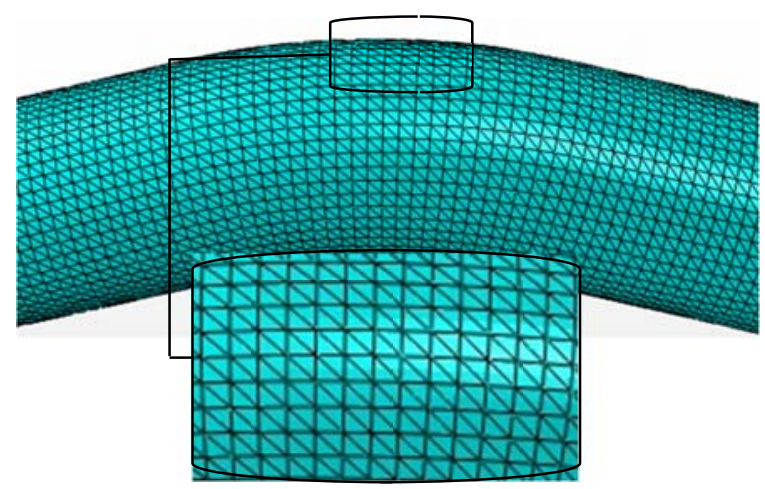

Figure 5: Mesh details of region in elbows.

According to the geometrical model of this analysis, the mesh structure is carried out by geometrically simple and identical elements in the two linear parts as well as in the elbow. However, in the elbow, the ovalization and the concentration of the stresses responsible for the damage in these zones, require us a refinement of the mesh. This allows better capture and in a precise way the maximum stresses and the initiation of the crack. The linear behavior of X70 steel was modeled using C3D8R three-dimensional brick elements to allow us to assess the effect of the studied parameters. Since the structure does not have the same geometries, the number of elements used is according to the angle of the elbow, with a number of elements of 8484 for a structure with a $30^{\circ}$ elbow and 8200 elements for a $60^{\circ}$ elbow as well as 7800 elements for the $90^{\circ}$ elbow. Figure (5) shows a detail of the mesh used for the calculations.

\section{STRESS ANALYSIS}

$\mathrm{T}$ he numerous stresses subjected to steel elbows as well as their typical geometry in tubular systems; make them an important and widely studied area of research. Hence the idea of studying their behavior under different bending moments and under the presence of both internal pressure and temperature. The geometric shape of the elbow causes an interdependence of effect with the mode of flexion. Indeed, depending on the case, these interdependent effects are locally concentrated in the geometry. A preliminary analysis of a stress state in this part of the study is opted in order to better identify the damage to these structures under various parametric or geometric effects. These stress states grouped together in the following curves are stopped just before the damage and with the same level of moment to apply. This numerical computation modality with the XFEM technique gave us the advantage with reliability of analyzing these geometric and complex loading situations without there being a problem of convergence. A preliminary analysis of the stress was carried out in order to select our choice on a tangential stress. This remains at a higher level, i.e. 1/3 more than the other components; radial and axial. Note that this stress is largely responsible for the damage to the structure. This is mentioned in the work of Spyros [20].

\section{Pressure effect on the stress}

Pressure is constantly present in the tubular structures. The type of loading applied in an elbow causes radial, axial and circumferential stresses. Tubular structures including the elbow, are largely subjected to circumferential stresses hence their representation in the figures, following the elbow circumference at $45^{\circ}$, the pressure effect is evaluated with the presence of temperature and bending moment in opening, closing and out of planes until the damage shown in the following figure.

This figure explains that the stress distribution is present at a certain fixed level of the bending moment where the damage to these different structures has not yet taken place. The purpose of this is to see the modality of damage caused by the level and nature of stress distribution in structures.

These figures show the bending mode effect of pressurized elbows at different levels on the tangential stresses taken around the circumference of the cross section of the elbow in the most stressed area and which is $15^{\circ}$ from the curvature of the elbow. It is noted that in all cases of bending moments that the elbow is stressed in compression and in tension along its circumference. We note a symmetrical distribution by contribution to both sides, that of the upper surface and lower surface, by pressure effect. In the open bending mode, the compressive stresses are localized in the upper surface and lower surface of the elbow while the tensile stresses are located in these sides. 


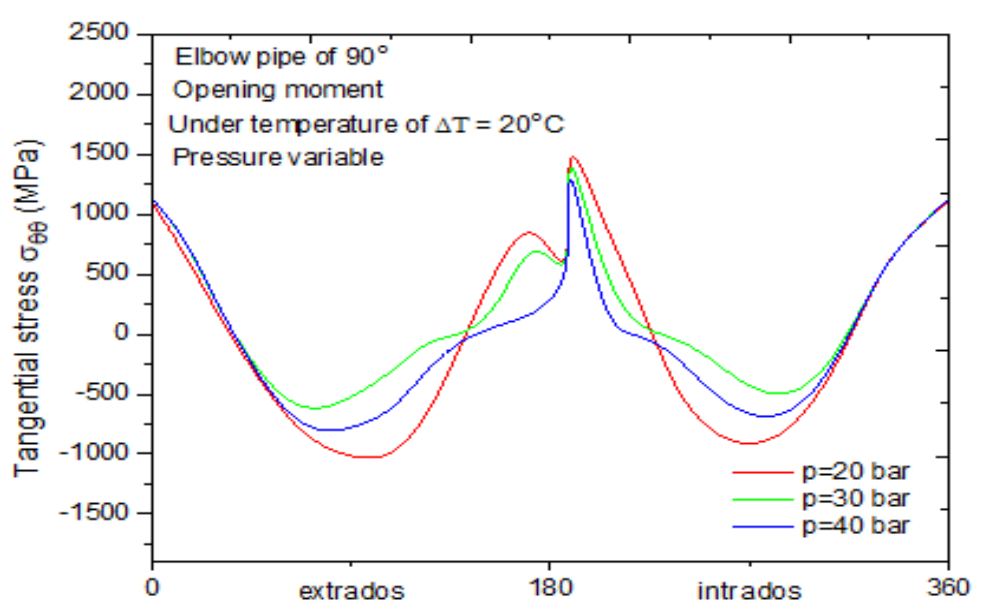

Circunference of the most effected area in the middle of the elbow $\left({ }^{\circ}\right)$

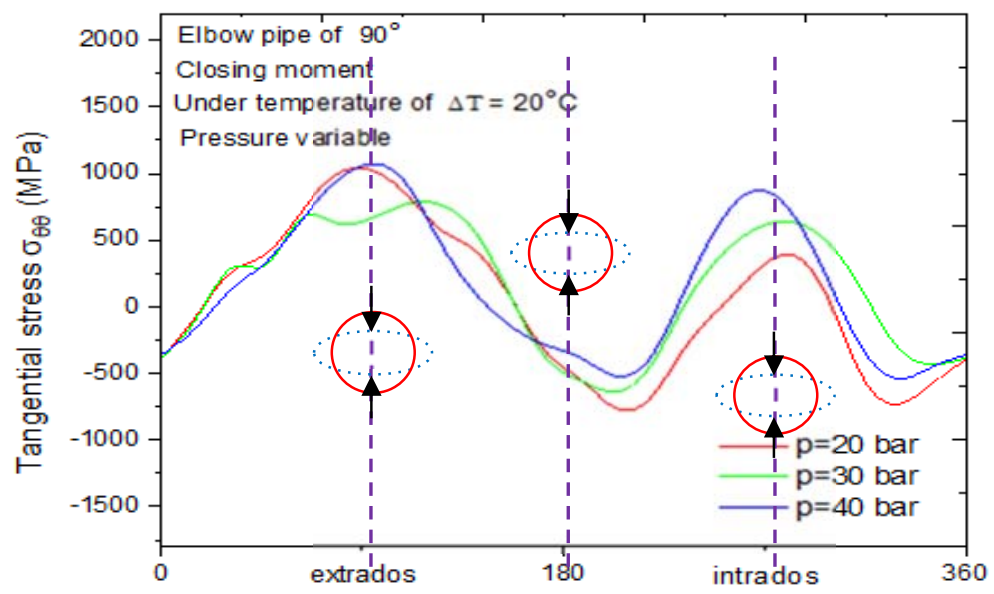

Circumference of the most effected area in the middle of the elbow $\left({ }^{\circ}\right)$

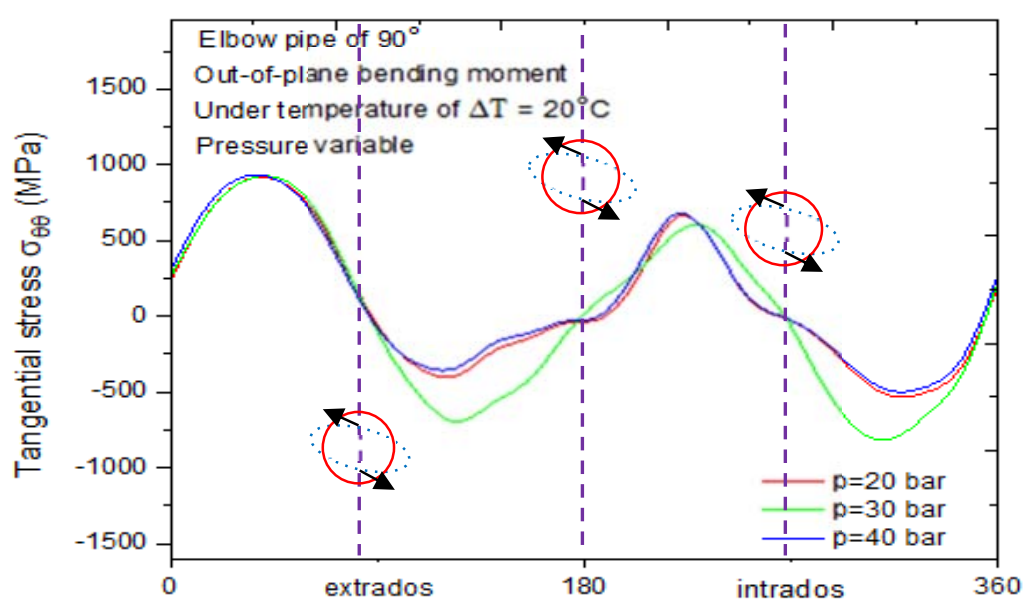

Circumference of the most effected area in the middle of the elbow $\left({ }^{\circ}\right)$

Figure 6: Tangential stress just before damage with effect of pressure in the case of angular elbows $90^{\circ}$ and temperature of $40^{\circ} \mathrm{C}$ under opening, closing and out-off-plan flexion moment. 


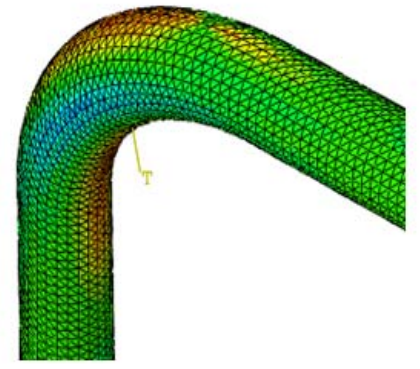

a) Opening moments

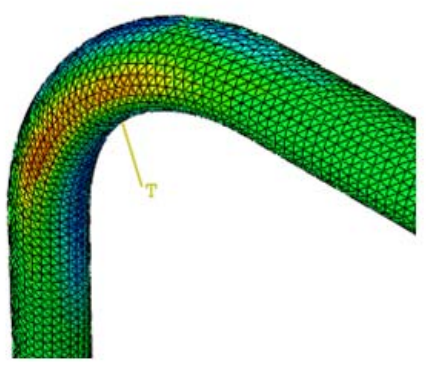

b) Closing moments

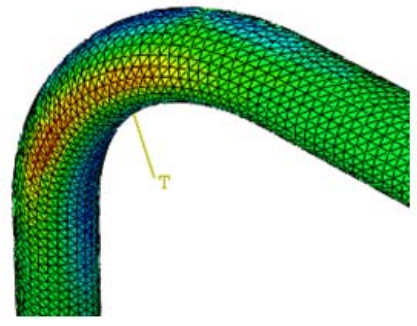

c) Out-of-plane moments

Figure 7: Tangential stresses in the elbows of angular $90^{\circ}$ for different imposed bending moments.

The tangential stresses in their nature are inversely distributed in the case of the bending moment in closure. On the other hand for the case of bending out of planes, the symmetry of distribution is the same between the two parts the upper surface and the lower surface except that the most stressed areas are oriented along a $45^{\circ}$ plane between the side of the elbow and its extrados. The pressure level effect appears clearly in the compression zones for the open and out-of-plane flexion mode and in the tension zones for the closed flexion mode. Note that the greater the pressure inside the structure, the greater the bending moment reactions and the more the thickness of the tubular structure is stressed at the elbow and in these sensitive areas those of the upper surface and the intrados as well as its sides.

\section{Effect of the angular elbows and loading condition on the stress}

In piping designs, the bend in tubular structures is presented by multiple angles, pressure and bending moment. Each angle is subjected to stress according to the geometry of the elbow, according to the circumference of the elbow at $45^{\circ}$, elbow at $90^{\circ}$ and at $30^{\circ}$. For the $60^{\circ}$ and $15^{\circ}$ elbow and for the $30^{\circ}$ elbow, the elbow angle effect is evaluated with the presence of temperature and bending moment in opening, closing and out of planes up to l damage shown in the following figure. It is always noted that the circumferential stresses play a large part in the stresses applied to the elbows.

Figure (8) explains the most stressed area in the elbow and subsequently the damage initiation area. It also explains the additive effect of temperature and more particularly that of pressure which directly influences the stress distribution under bending moment. The distribution of tangential stresses was selected in this analysis because it has higher levels than other stresses, radial and axial. It is clearly noticed that the stresses are more important for the most closed elbow except for the out-of-plane bending. The stresses change their nature from compression to tension along the circumference of the elbow for all three modes of flexion except that their areas of compression and tension change from one flex mode to another. It should be noted that in the case of bending in opening, the areas, which are closest to the sides of the elbow, are subjected to significant tensile stresses, and at the same level are the compressive stresses in the upper surface and the lower surface. This stress state is inversely distributed in these zones for the case of bending in closure, and for the case of bending out of planes. The most stressed areas are angularly offset and are oriented along a $45^{\circ}$ plane between the side of the elbow and its extrados.

\section{DAMAGE ANALYSIS}

$\mathrm{B}$ y virtue of these numerous advantages, elbows are frequently present in tubular structures, by their geometry and by the permanent presence of pressure and also under the various modes of stress. However, they are much more exposed to their damage than straight tubular structures. Under thermo-mechanical behavior, the damage of these structures quickly becomes more favorable; hence, our problem of identifying their resistance capacity under the effect of various parameters, those of the mode of applied moment, of applied pressure and of dimension of the elbows. It is noted that according to the modes of bending, the resistance of systems is the resistance of the elbow itself in the system straight tube-elbow-straight tube.

\section{Effect of the angular elbows and loading condition on the failure of structure}

The geometric configuration of the elbow in the straight tube-elbow-straight tube system conditions the structural response to loading as well as their resistance levels. In all cases, the presence of pressure and temperature act as an accelerator to 
damage the structure. The angle of the elbow changes the shape not only of the elbow itself but also of the overall structure which is stressed in these different modes of flexion that of opening, closing and out of planes. Under a pressure of $30 \mathrm{bar}$ and at the same temperature of $40^{\circ} \mathrm{C}$, the angle effect of the elbow is well presented in the structural response up to their damage and under different bending modes.

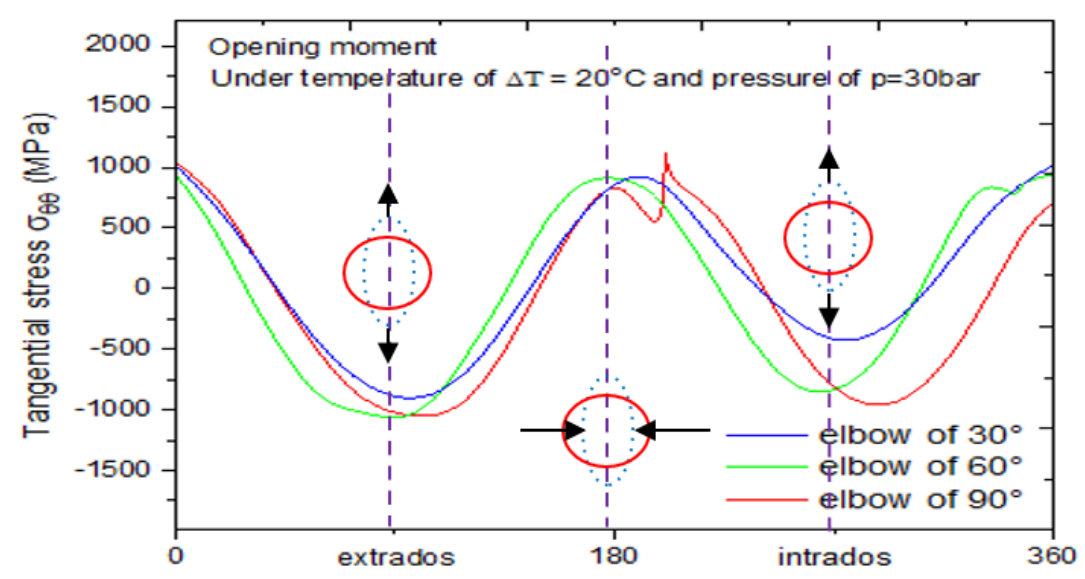

Circumference of the most effected area in the middle of the elbow $\left({ }^{\circ}\right)$

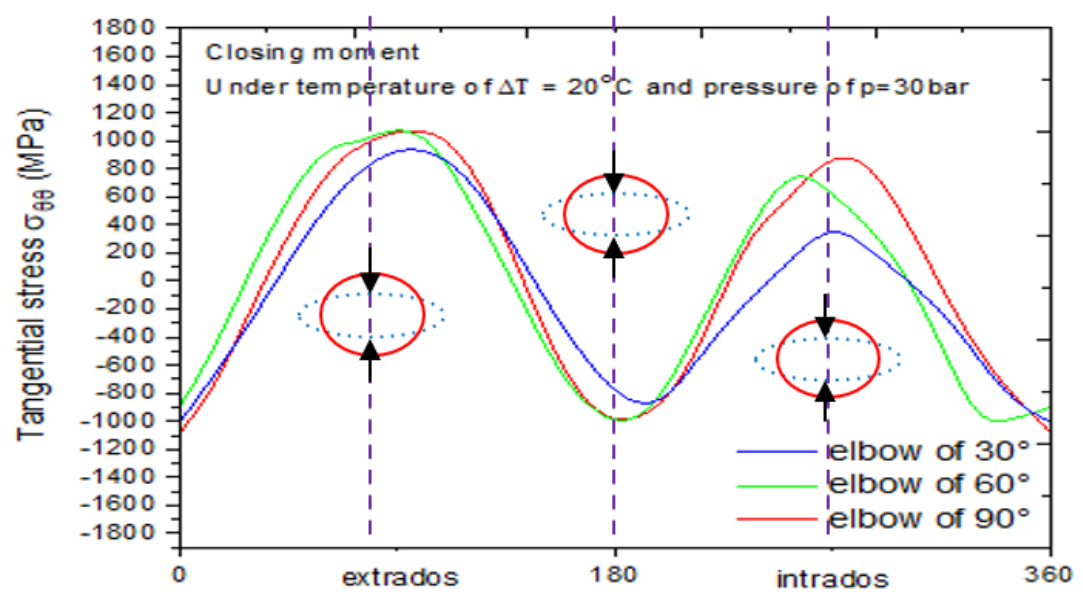

Circumferenœ of the most effected area in the middle of the elbow $\left({ }^{\circ}\right)$

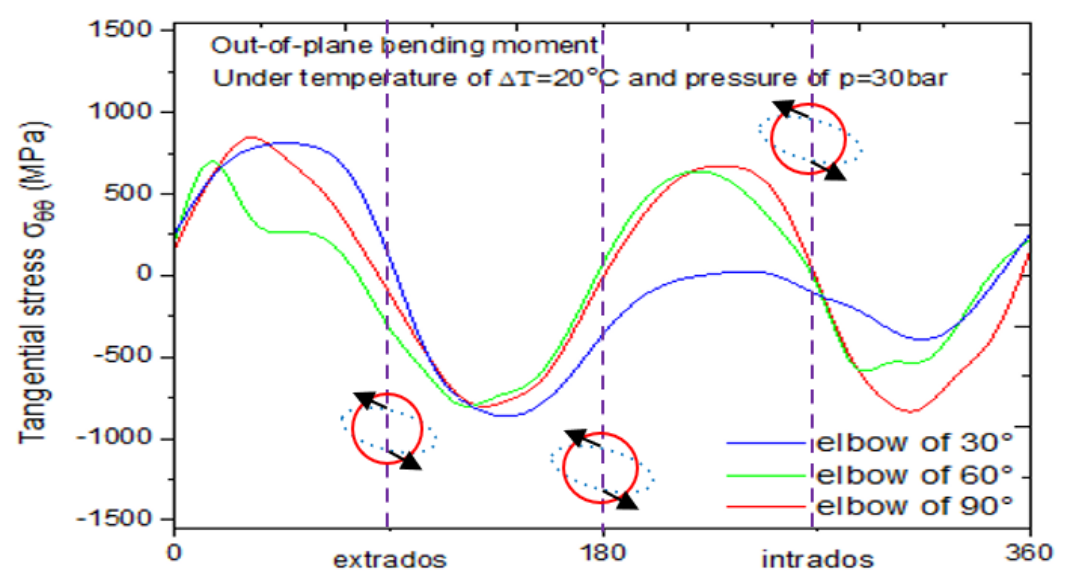

Circumference of the most effected area in the middle of the elbow $\left({ }^{\circ}\right)$

Figure 8: tangential stress just before damage with effect of angular elbows in the case of temperature $40^{\circ} \mathrm{C}$ and pressure of 30 bar under opening, closing and hors plans flexion moment. 


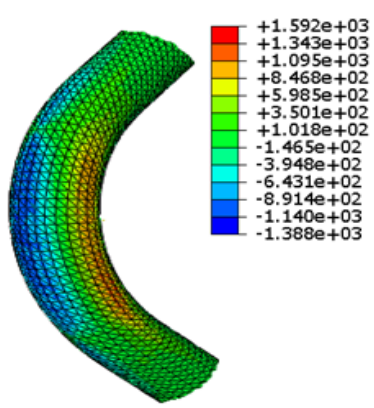

a) Elbows of $90^{\circ}$

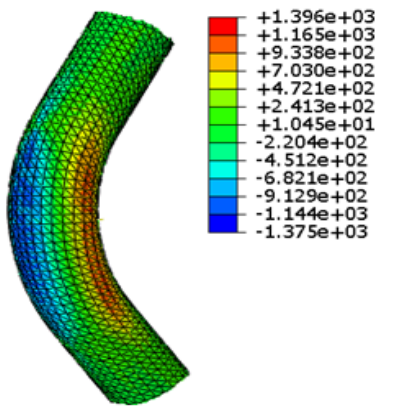

b) Elbows of $60^{\circ}$

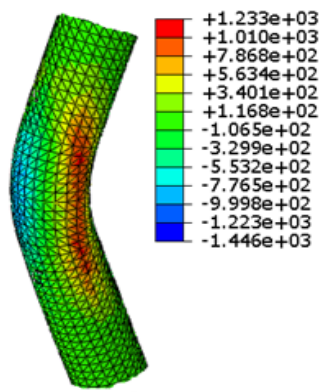

c) Elbows of $30^{\circ}$

Figure 9: Tangential stresses in the elbows of angular $90^{\circ} 60^{\circ}$ and $30^{\circ}$ in the case of closing bending moments.

Figure (10) shows that the response of the elbow to the bending moment is nonlinear up to the maximum moment with different levels, widely different by the effect of the angle of the elbow. We notice that at a certain moment, this level is maximum. This explains the resilience of the system. The rotational displacement of the system becomes independent of the applied bending moment, in particular for the case of out-of-plane bending. It is also noted that the same nature of response of the structure to the bending moment is marked for the different angles of the elbow as for the different modes of bending, the more the angle of the elbow is open, the more the moment is important to damage the structure. In all these different cases, the damage occurs after the transverse ovalization of the elbow. Depending on the bending mode, this ovalization takes several planes in the bend, the most dangerous is that which presents itself with the lowest damage moments and which are, in the case of closing moments.
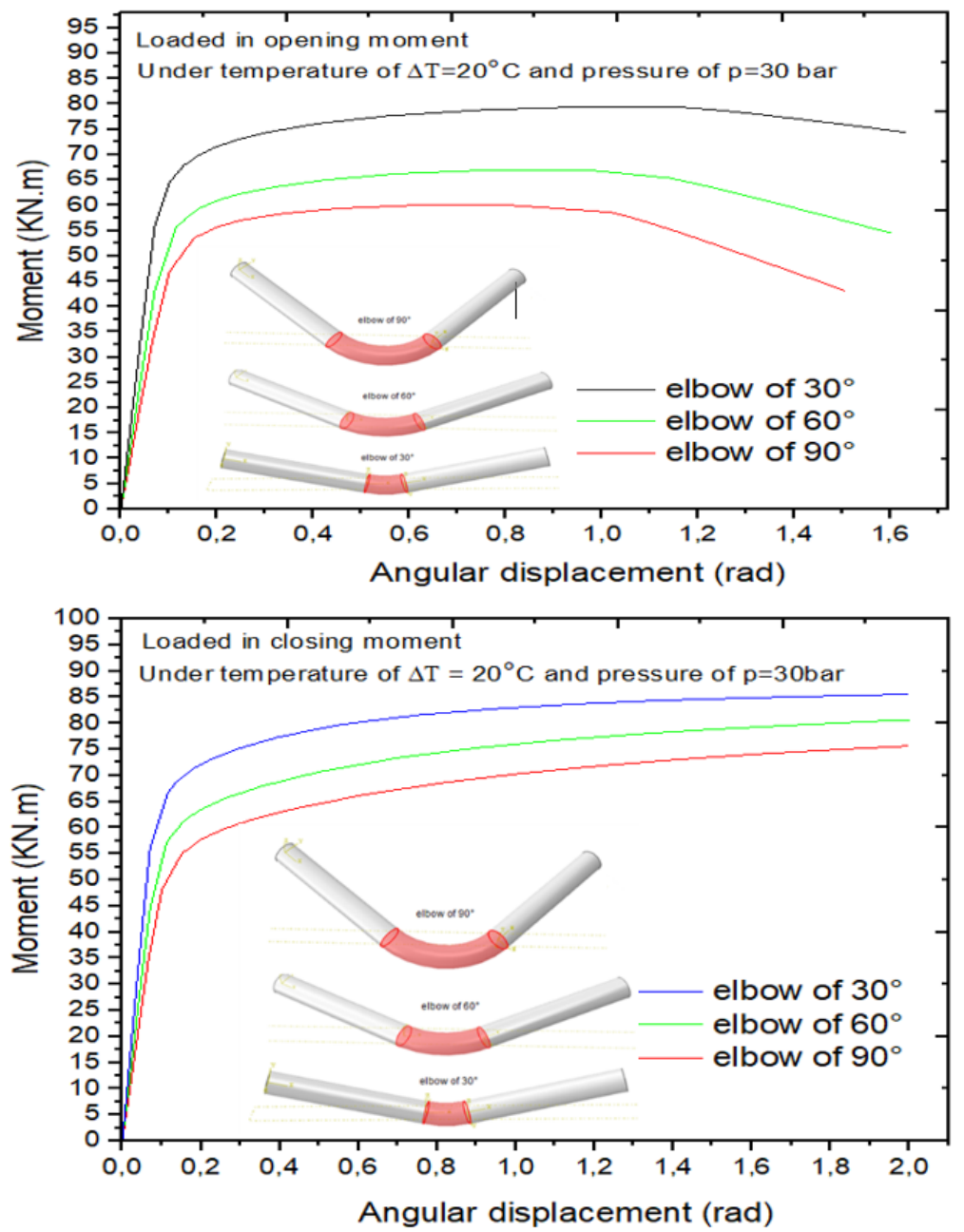


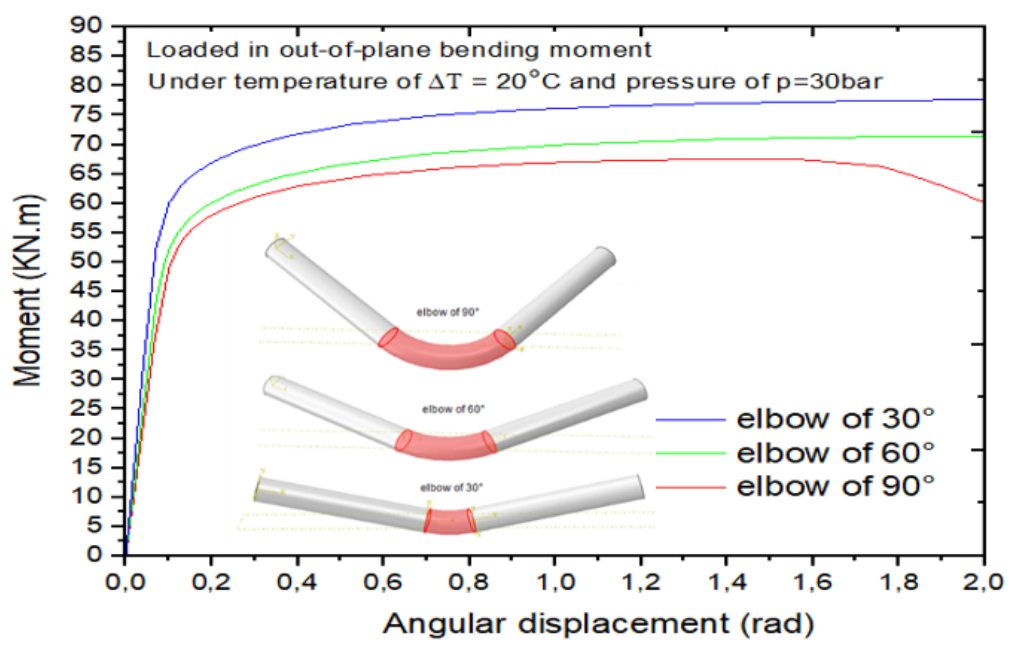

Figure 10: damage moment-rotation curve with effect of angular elbows in the case of pressure $30 \mathrm{bar}$ and temperature of $40^{\circ} \mathrm{C}$ under opening, closing and out-off plan flexion moment

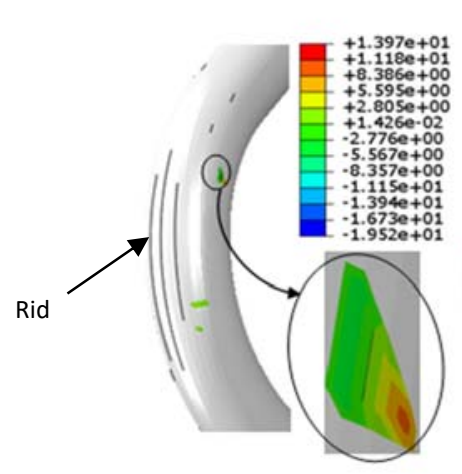

a) Elbows of $90^{\circ}$

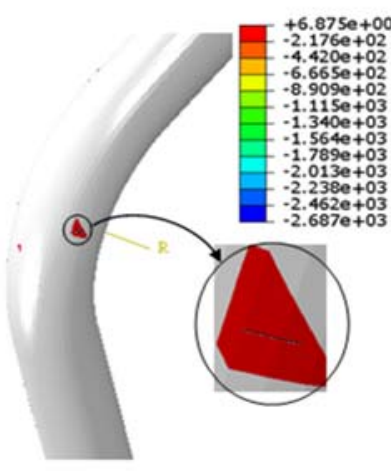

b) Elbows of $60^{\circ}$

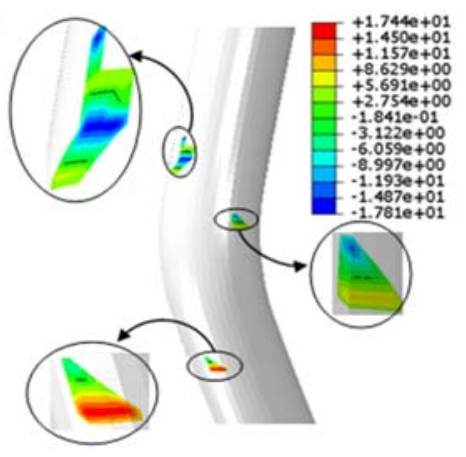

c) Elbows of $30^{\circ}$

Figure 11: Damage of the elbows of angular $90^{\circ} 60^{\circ}$ and $30^{\circ}$ in the case of closing bending moments.

In this figure (11), the damage zones caused by both the pressure effect and the closing bending moment effect have been presented, for the various cases for the angle of the elbow: $30^{\circ}, 60^{\circ}$ and $90^{\circ}$. This presentation has shown that these zones are the same, which are presented in the structure by the stress concentrations just before the damage. Their mode, as shown in figure (11), differs depending on the angle of the elbow. For the $90^{\circ}$ elbow, we notice wrinkles in the upper surface due to high tension in this area, while for the $60^{\circ}$ elbow, damage is found only in the sides of the elbow, while the $30^{\circ}$ elbow ${ }^{\circ}$ presents with several areas of damage. The tubular cross section of the elbow is subjected to internal pressure as a reaction to tensile forces. These are finely localized according to the angle of the elbow and the bending moment. Once a crack appears in an area, the structure becomes destabilized in its resistance, resulting in the appearance of several areas of damage, especially for the $30^{\circ}$ elbow.

\section{Effect of the pressure with different loading condition on the failure of structure}

In this part of the study, we used dimensional conditions of the $90^{\circ}$ elbow because it has low resistance compared to others such as the $30^{\circ}$ and $60^{\circ}$. The temperature is at a level of $40^{\circ} \mathrm{C}$ and is the same in all the different cases and this to have a response of the structures until their damage with a thermo-mechanical behavior. However, depending on the conditions in which they occur, the temperature and the pressure weaken the structure by accumulating charges. The mode of flexion and the angle of the elbow take place as comparative parameters to which the resistance capacity is related. The response and evolution of the system to thermo-mechanical damage under the evaluative parameters are presented below by the torque curves. 

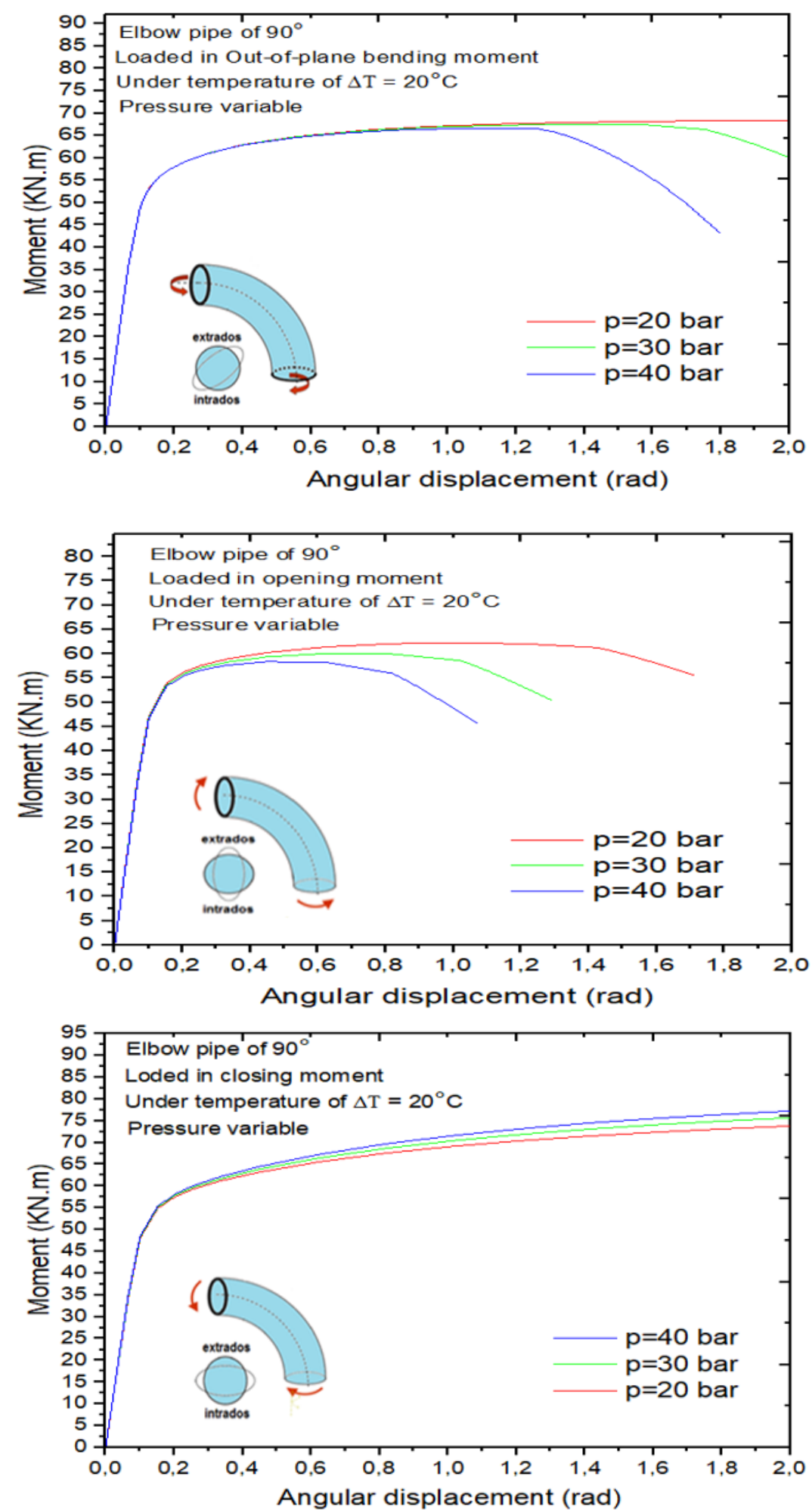

Figure 12: Damage moment-rotation curve with effect of pressure values in the case of angular elbows $90^{\circ}$ and temperature of $40^{\circ} \mathrm{C}$ under opening, closing and hors plans flexion moment

We see in Figure (12) the same responses up to the critical moment with slightly different levels of damage, which corresponds to clearly significant angular displacements, especially for the case of the bending moment in opening and closing. The structure with the greatest pressure does not allow a large deformation capacity. The lower the pressure, the 
more it allows the deformation of the structure and the more damage is delayed. One notes the opposite for the structure under the mode of bending except plans. A localized ovalization of the pipe of the elbow in the middle is perpendicular to the bending planes for the case of moment in closing and is parallel to the planes of bending for the case of moment in opening, and it is inclined for the case of bending out of planes. This oval deformation describes the response of the structure, which leads to rapid damage by the additive effect of temperature and pressure. The failure therefore occurs when the elbow is stressed by its thickness to high tensions at the level of the lower surface of the elbow in the case of the opening and at the level of the upper surface as well as on the sides of the elbow for the case closing. On the other hand, in the case of out of planes, it occurs throughout the part of the elbow.

The areas of damage caused under the effect of different bending modes, with a pressure of $30 \mathrm{bar}$ and a bend angle of $30^{\circ}$, are shown in Figure (13). These zones always remain dependent on the bending mode. In all cases, the areas of stress concentration are the areas of initiation of damage. Their modes, as shown in figure (13), differ depending on the bending moments. At the time of opening and during high tensions, the damage is localized in the sides of the elbow. Also for the moment out of plans but which shifted from the middle of the elbow. On the other hand, for the moment of closure, we notice that there are several damage initiation zones. Internal pressures stress the elbow thickness as a reaction to the tensile forces; these forces are localized according to the bending moment.

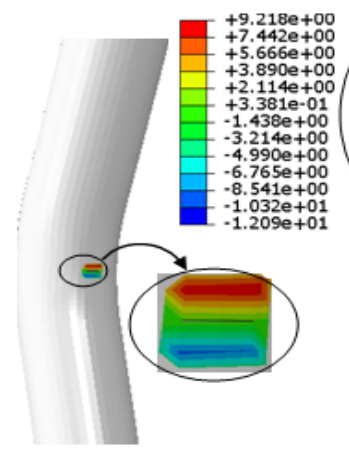

a) Opening moment

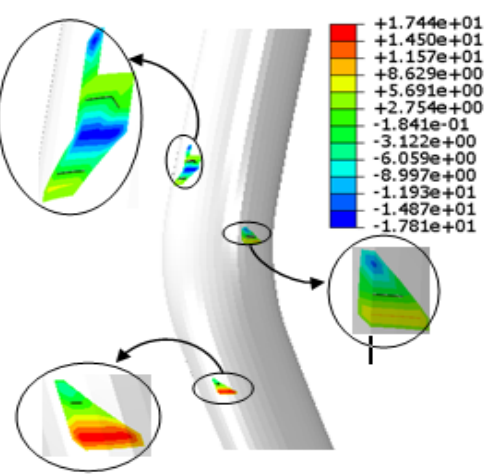

b) closing moment

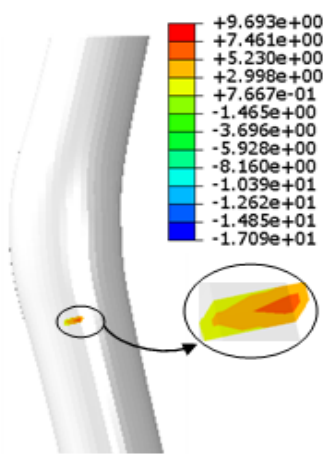

c) Out of plane bending moment

Figure 13: Damage in the pressure of 30bar and elbows of angular $30^{\circ}$ in the different case of bending moments.

\section{CONCLUSION}

$\mathrm{D}$

espite the numerical complications of this work of the model studied, such as: geometric and complex loading conditions (combined bending with internal pressure) and in fabric and geometrically tubular composite structures, the damage criterion clearly presented its effectiveness. The results obtained allowed us to gain an understanding of the interaction of defects and to compare the different parameters influencing the damage of our studied structures.

$\checkmark$ For our numerical result under application of a moment in the form of angular displacement of $60^{\circ}$ as well as a reinforcement of thickness up to $6.4 \mathrm{~mm}$, we found according to the studied case, a critical moment between $65 \mathrm{kNm}$ and $85 \mathrm{kNm}$ for a pressure between 20bar and $40 \mathrm{bar}$. It is a difference of $11 \mathrm{KN}$ from the work of Karamanos where he used thickness of $3 \mathrm{~mm}$ and diameter of $270 \mathrm{~mm}$.

$\checkmark$ The X-FEM technique has proven its effectiveness as well as damage criterion, given that our structure is made with solid finite elements in three dimensions and that this technique is no longer limited in its use in interfaces such as VCCT and CZM and it is independent of the architecture of the mesh. In our case, it does not require the presence of a pre-crack.

$\checkmark$ Purely pressurized tubular structures are circumferentially stressed in tension more than by other stresses, these stresses are more important than others are, and they can change the nature of the tension at compression depending on the loading and geometry conditions as in our elbow case.

$\checkmark$ The transverse oval plane of the elbow is according to the flexion mode in which it is subjected.

$\checkmark$ The open bend allows greater angular displacements with higher critical bending moments. 
$\checkmark$ The less pressurized the system is, the more the structure supports angular displacements and significant bending moments.

$\checkmark$ Plasticization of the metal occurs at the levels of the ovality, which explains the response of the structure in angular rotation under the bending moment.

$\checkmark$ By the presence of pressure and the bending moment, ovalization takes place in the middle of the elbow and the area of the damage.

$\checkmark$ The temperature weakens and accelerates the damage to the structure by accumulation of mechanical loads.

In light of the above arguments, this work provided a suitable modeling for more problems, on the predictions of the damage in elastic-plastic behavior of different geometries in X70 steel and it may be of interest for further research.

\section{REFERENCES}

[1] Von Karman, T., (1911). Uber die Formuanderung dunnwandiger Rohre, Zeit. Des Verienes. deutcher Ingenieur,55, pp. 1889-1895.

[2] Rodabaugh, E. C., and George, H. H., (1957). Effect of Internal Pressure on the Flexibility and Stress Intensification Factors of Curved Pipe or Welding Elbows, Trans. ASME, 79, pp. 939-948.

[3] Karamanos, S. A., Tsouvalas, D., and Gresnigt, A. M., (2006). Ultimate Bending Capacity and Buckling of Pressurized 90 Deg Steel Elbows, Journal of pressure vessel technology, 128(3), pp. 348-356. DOI: 10.1115/1.2217967.

[4] Sobel, L. H., and Newman, S. Z., (1980). Comparison of Experimental and Simplified Analytical Results for the InPlane Plastic Bending and Buckling of an Elbow, Journal of pressure vessel technology, 102(4), pp. 400-409.

DOI: $10.1115 / 1.3263351$.

[5] Dhalla, A. K., (1987). Collapse Characteristics of a Thin-Walled Elbow,” Journal of pressure vessel technology, 109(4), pp. 394-401, DOI: 10.1115/1.3264922.

[6] Gresnigt, A. M., (1985). Preofresultaten van Proeven op Gladde Bochten en Vergelijking Daarvan met de in OPL 85333 Gegeven Rekenregels, Institute for Construction Materials and Structures, TNO-IBBC, Report No. OPL 85-334, Delft, the Netherlands.

[7] Auwal, M., Ercan, S.., (2014). Experimental and Numerical Study of Energy Absorption Behavior of Glass and Carbon Epoxy Composite Tubes under Static Compressive Loading, IOSR Journal of Applied Physics, 6(4), pp. 30-37, DOI: $10.9790 / 4861-06433037$.

[8] Lemaître, J., Chaboche, J.L., (1988). Mécanique des Matériaux Solides, Edition Dunod, 2ème édition,France.

[9] Lachaud, F., Michel, L. (1997). Etude de l'endommagement de matériaux composites carbones à matrice thermodurcissable et thermoplastique, Mécanique Industrielle et Matériaux, 50(2).

[10] Abdelouahed, E., Mokhtari, M., Benzaama, H. (2019). Finite Element Analysis of the thermo-Mechanical Behavior of composite Pipe Elbows under Bending and Pressure loading, Frattura ed Integrita Strutturale, 49, pp. 698-713, DOI: $10.3221 /$ igf-esis.49.63

[11] Shao, Z. S., (2005). Mechanical and Thermal Stresses of a Functionally Graded Circular Hollow Cylinder With Finite Length, International Journal Pressure Vessels Piping, 82(3), pp. 155-163. DOI: 10.1016/j.ijpvp.2004.09.00.

[12] Kandil, A., El-Kady, A. A., and El-Kafrawy, A. (1995). Transient Thermal Stress Analysis of Thick- Walled Cylinders, Int. J. Mech. Sci., 37(7), pp. 721-732. DOI: 10.1016/0020-7403(94)00105-S.

[13] Greenstreet, W. L., (1978). Experimental Study of Plastic Responses of Pipe Elbows”, ORNL/NUREG-24 Categoty NRC5.

[14] Suzuki, N, and Nasu, M., (1989). Non-Linear Analysis of Welded Elbows Subjected to In-Plane Bending”, Comput. Struct, 32(3/4), 871-881. DOI: 10.1016/0045-7949(89)90371-4

[15] Tan, Y, Matzen, V. C., and Yu, L. X., (2002). Correlation of Test and FEA Results for the Nonlinear Behavior of Straight Pipes and Elbows", Journal of pressure vessel technology, 124(4), pp. 465-475. DOI: 10.1115/1.1493806.

[16] Shalaby, M. A., and Younan, M. Y. A., (1999). Effect of Internal Pressure on Elastic-Plastic Behavior of Pipe Elbows Under In-Plane Opening Bending Moments, Journal of pressure vessel technology, 121(4), pp. 400-405.

[17] Karamanos, S. A., Giakoumatos, E., and Gresnigt, A. M., (2003). Nonlinear Response and Failure of Steel Elbows Under In-Plane Bending and Pressure, Journal of pressure vessel technology, 125(4), pp. 393-402.

[18] Hilsenkopf, P., Boneh, B., and Sollogoub, P. (1988). Experimental Study of Behavior and Functional Capability of Ferritic Steel Elbows and Austenitic Stainless Steel Thin-Walled Elbows, Int. J. Pressure Vessels Piping, 33(2), pp. 111128. DOI: $10.1016 / 0308-0161(88) 90065-8$.

[19] ABAQUS, Abaqus Version (2009). 6.9Documentation. Providence, RI: Dassault Systems Simulia Corporation. 
[20] Karamanos, S.A. (2016). Finite Element Analysis of the Mechanical Behavior of Mitered Steel pipe elbows under bending and pressure, Journal of pressure vessel technology. DOI: 10.1061/9780784479957.117.

[21] Bouledroua, O., Ouled Mbereick, M., Azari, Z., Hadj Meliani, M. (2015). Qualification d'un Acier API 5L X70: Etude Expérimentale et Validation Numérique, Journal of Nature \&amp; Technologie, 13, pp. 34-39. 